\title{
Generation IV Material Issues - Case SCWR
}

\author{
Sami Penttiläa ${ }^{a}$ Aki Toivonen ${ }^{a}$, and Liisa Heikinheimo ${ }^{b}$ \\ ${ }^{a}$ Materials and Building, Technical Research Centre of Finland \\ P.O. Box 1000, FI-02044 VTT, Espoo, Finland, e-mail: sami.penttila@vtt.fi \\ ${ }^{b}$ Teollisuuden Voima Oyj, Helsinki,Finland
}

Keywords: GenIV, supercritical water, corrosion, stress corrosion cracking, austenitic alloys, ODS steel, SSRT

\section{ABSTRACT}

Generation IV nuclear power concepts have become an active research topic all over the world during the last 5 - 10 years. There are six concepts accepted by the GenIV international forum (GIF) with the common aims to promote both efficiency and safety of the technology. New concepts will offer attractive features but at the same time they also bring new and demanding challenges e.g. for the materials technology due to increased operating temperatures and irradiation doses as well as more aggressive coolants and/or longer life time expectations than of GenII and GenIII plants. In this paper an overview of the material issues is given with special emphasis on one of the 6 concepts namely the supercritical light water reactor concept (SCWR).

This paper reviews the performance of commercial candidate materials for SCWR in-core applications focusing on the corrosion and stress corrosion cracking issues (SCC) based on work within the Euratom HPLWR Phase 2 (High Performance Light Water Reactor Phase 2) project. General corrosion (i.e., oxidation rate tests) and SCC tests have been performed on selected iron and nickel based alloys at $500^{\circ} \mathrm{C}$ and $650^{\circ} \mathrm{C}$ in supercritical water under the pressure of $25 \mathrm{MPa}$ with oxygen concentration of $125-150 \mathrm{ppb}$ in all tests. The oxidation behaviour was studied using weight gain measurements and scanning electron microscopy (SEM and EDS). The SCC tests were slow strain rate tests (SSRT) performed using a step motor controlled loading device. The samples were loaded with a strain rate of $3 \times 10^{-7} \mathrm{~s}^{-1}$.

Ferritic-martensitic (F/M) steels containing chromium have generally good resistance to stress corrosion cracking. However, they suffer from fast oxidation under the SCW conditions. Austenitic stainless steels and Ni-based alloys have better oxidation resistance but, on the other hand, are generally considered more susceptible to stress corrosion cracking. The SSRT tests reported in this paper showed differences in the SCC susceptibility. The commercial austenitic stainless steels $316 \mathrm{NG}, 1.4970,347 \mathrm{H}$ are not as susceptible as expected to $\mathrm{SCC}$ at $500^{\circ} \mathrm{C}$ whereas an experimental creep resistant austenitic stainless steel BGA4 showed considerable susceptibility to intergranular SCC. At $650^{\circ} \mathrm{C}$, the commercial austenitic stainless steels were observed to be potentially SCC susceptible. The high chromium ODS (Oxide Dispersion Strengthened) steel PM2000 did not show SCC at either of the test temperatures.

Alloys with high nickel content were not considered for the SCC studies because Ni has a strong negative effect on neutronics in the reactor core. Therefore, the present candidate materials for the core internals of the SCWR are austenitic stainless steels, which have a good enough oxidation resistance up to $500^{\circ} \mathrm{C}$. The high chromium $(20 \% \mathrm{Cr})$ ODS alloy is considered for the fuel rod cladding because of its good oxidation and $\mathrm{SCC}$ resistance up to $650^{\circ} \mathrm{C}$.

\section{INTRODUCTION}

Today there are activities in many countries aiming to upgrade old nuclear power plants or extend the plant life or to start even new projects. New projects have been started especially in China (more than $30 \mathrm{GW}$ to be built by 2020), India (more than $20 \mathrm{GW}$ by 2020) and Korea ( $9 \mathrm{GW}$ by 2015) but today also in USA and 
Europe. The old and presently built plants are of generation 2 or 3 . In recent years the research of new generation reactors, generation 4 (GenIV from now on), has been in focus. This new interest in nuclear power has launched lots of different projects related to GenIV concepts.

There are today six GenIV nuclear power concepts that are listed in GenIV International Forum (GIF) research agenda:

- Very high temperature reactor (VHTR)

- Supercritical-water-cooled reactor (SCWR)

- Gas-cooled fast reactor (GFR)

- Lead-cooled fast reactor (LFR)

- $\quad$ Sodium-cooled fast reactor (SFR) and

- Molten salt reactor (MSR).

Research on all the concepts has started in main participating countries and partners: USA, Japan, Korea, Canada and Euratom, with contributions from China, South Africa, India and individual European countries like France. Today the R\&D activities are concentrating on basic technologies and concept development. The design phase is started next and the demonstration is expected to take place first in France for the SFR type reactor concept by 2020 .

The material technology and plant life assessment for these concepts will be developed time wise and technologically between the present nuclear power concepts (mainly GenIII) and the development of fusion technology. The operating parameters of these new concepts are summarised on a general level in Fig. 1. The data is based on current knowledge and discussions in the GIF forums, Heikinheimo et al. (2007).

The SCWR concept is very attractive due to the fact that it offers a high efficiency and the basic concept is close to the present LWRs (Light Water Reactors). Added to this, many components can be adopted straight from supercritical water fossil power plants (SCFPP). The coolant outlet temperature is about $500^{\circ} \mathrm{C}$. The fuel cladding peak temperature can be as high as $620-630^{\circ} \mathrm{C}$. The operating temperature, irradiation, and small wall thicknesses of the core components is a combination which exhibits requirements for internal core component materials more difficult to fulfil than in conventional SCFPPs. The most difficult component is the fuel cladding. Zr-alloys used in present day LWRs oxidise too quickly at the SCWR temperatures. The choices will be mainly a modified stainless steel or a novel ODS alloy. The other core components are operating at up to $500^{\circ} \mathrm{C}$, which is in the upper limit of conventional austenitic stainless steels. The main operating parameters of SCWR concept are shown in Fig. 2 along with the principal environmental challenges.

The fluid characteristics can be seen in Fig. 3. The critical point is at $374^{\circ} \mathrm{C}$ and $22.1 \mathrm{MPa}$. At the critical point there is a dramatic change in most of the physical properties of water, e.g., density, specific heat, viscosity etc. Therefore, water chemistry (including radiolysis) and related corrosion phenomena will be a challenging and important research topic for the SCWR concept because the existing subcritical LWR data has very limited applicability.

The EU project "High Performance Light Water Reactor Phase 2" (HPLWR Phase 2) aims to design a feasible SCWR. One of the main tasks is to characterize and identify suitable construction materials for reactor pressure vessel internal components.

At the moment, there are several papers in open literature considering general corrosion and stress corrosion cracking (SCC) of candidate materials for SCW. Tests have been conducted in a wide range of conditions. However, temperatures used in the experiments, both general corrosion and SCC, have been systematically lower than the estimated peak temperature of the cladding. Based on literature and results obtained during the HPLWR Phase 2 project, the main application for F/M-steels will be the reactor pressure vessel (RVP) and excore components, like piping where temperature is low enough $\left(\leq 400^{\circ} \mathrm{C}\right)$, Penttilä et al. (2008). The austenitic stainless steels are studied for the internals, fuel cladding and heat exchangers. Both Ni-based alloys and ODSmaterials may be alternatives to replace austenitic steels at high operating temperatures or severe corrosion environments. However, Ni-based alloys can be excluded in the case of core components due to high Ni content. High Ni content affects negatively to core neutronics due to effective absorption of neutrons. 


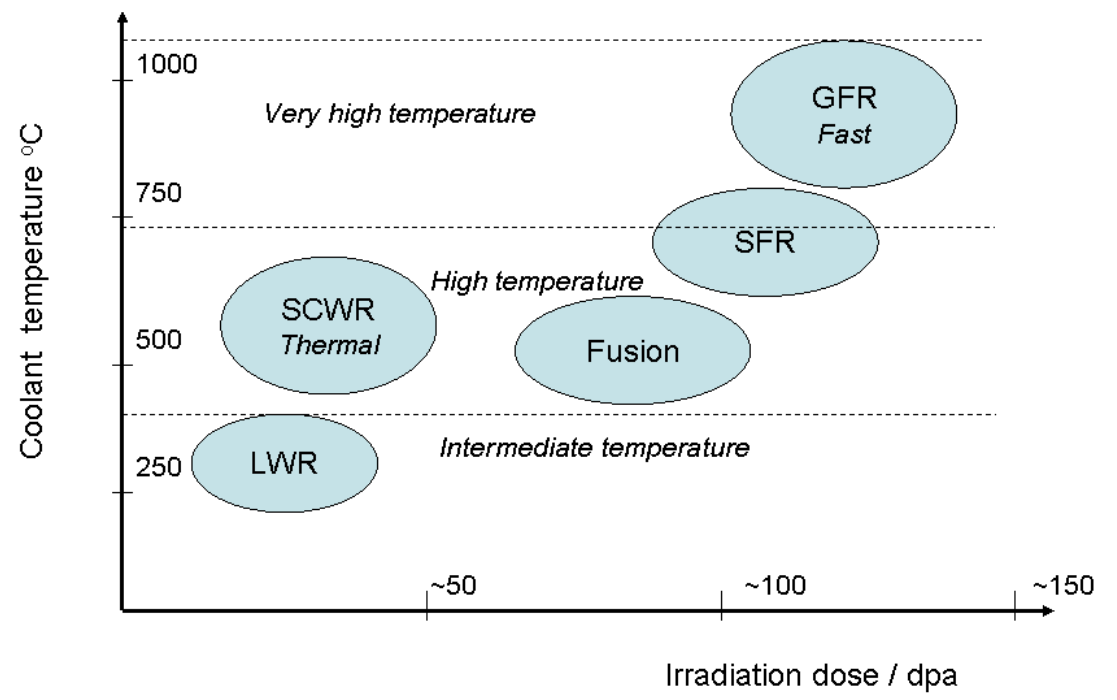

Figure 1. General features of GenIV concepts compared to present LWRs and proposed characteristics of Fusion technology. Coolant temperatures and irradiation doses are selected as most severe operating parameters, Heikinheimo et al. (2007).

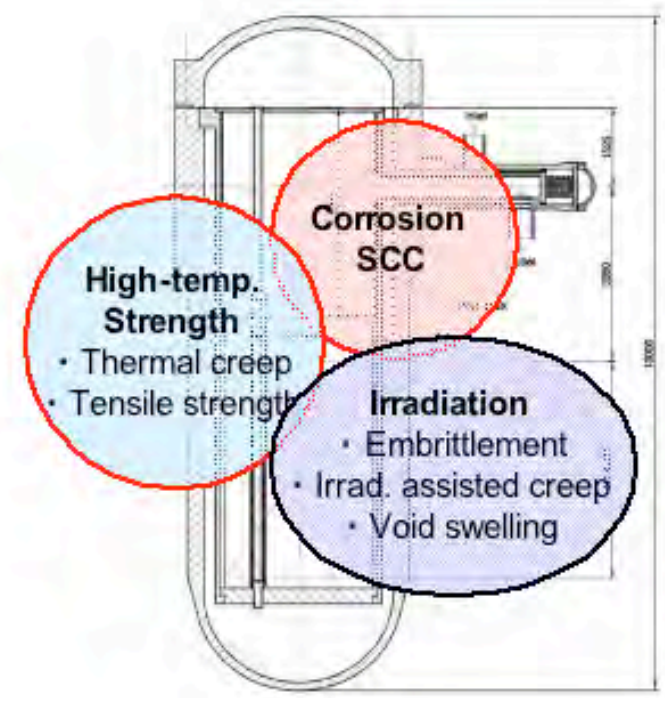

HPLWR Data (5 th FP)

Gross power

Svstem nressure

$1000 \mathrm{MW}_{8}$

$25 \mathrm{MPa}$

Figure 2. The operation parameters of SCWR concept based on Euratom project HPLWR, Heikinheimo et al. (2007).
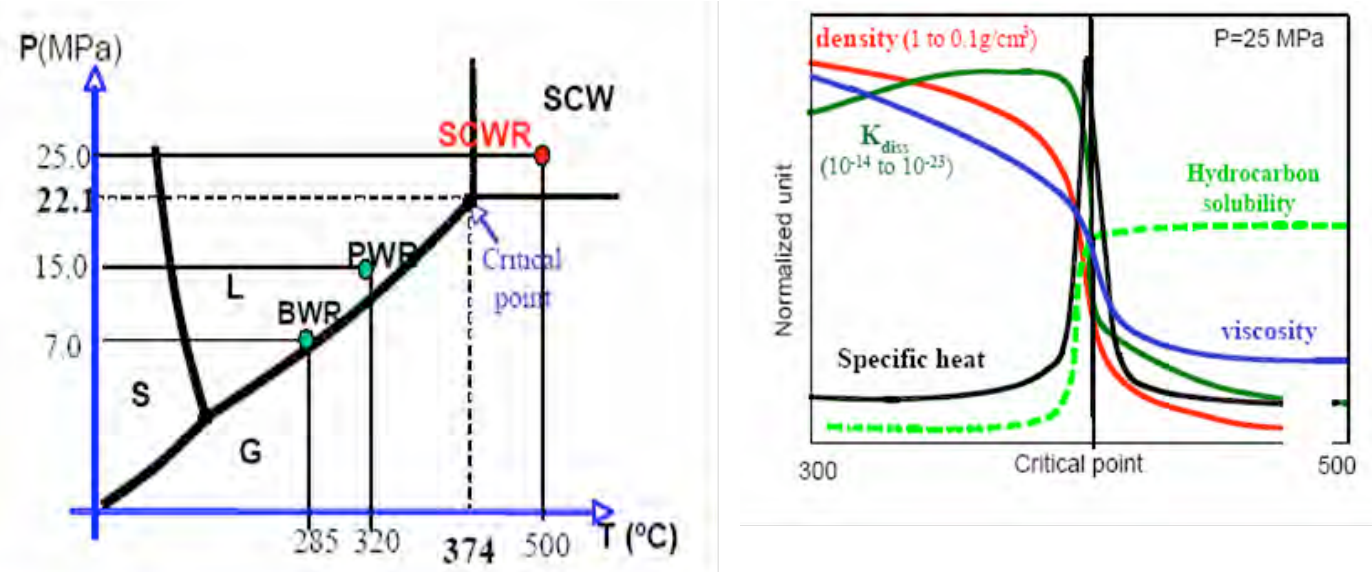
Figure 3. The stability diagram of $\mathrm{H}_{2} \mathrm{O}$ as a function of temperature and pressure, typical operation values for BWR, PWR and SCWR are placed in the schema (left). The changes of different $\mathrm{H}_{2} \mathrm{O}$ properties across the SC-point can be seen in the right schema, Heikinheimo et al. (2007).

\section{OBJECTIVES}

The objectives of this work were to clarify the general corrosion resistances of candidate materials (initial results were published in Penttilä et al., 2008) and also to determine the stress corrosion susceptibility of materials picked from the original selection. For some of the test materials no literature data was available and some test materials were selected for reference purposes.

\section{EXPERIMENTAL PROCEDURES}

\subsection{Materials and specimens}

General corrosion tests were performed on a number of ferritic-martensitic (F/M), ODS and austenitic stainless steels and nickel base alloys, Table 1 .

The general corrosion tests were performed on coupons with, in most cases, the dimensions of $25 \times 15 \times 5$ $\mathrm{mm}$. In the case of 1.4970, also short tubular specimens cut from a fuel cladding used in European sodium cooled fast breeders were used. Different polishing levels were applied for the general corrosion specimens.

Some of the materials used in general corrosion tests were selected for SCC testing. The SCC tests were SSRT (slow strain rate tensile) tests. Specimens for the SSRT tests were electric discharge machined into 30 $\mathrm{mm}$ long plate type tensile specimens with a gauge section of 2,0 by $1,5 \mathrm{~mm}$. The specimen geometry and dimensions are shown in Fig. 4. Before the tests, the gauge sections of the specimens were polished mechanically.

Table 1. Chemical compositions of studied alloys (w-\%). 


\begin{tabular}{|l|r|r|r|r|r|r|r|r|r|}
\hline & $\mathbf{C}$ & $\mathbf{S i}$ & $\mathbf{M ~ n}$ & $\mathbf{S}$ & $\mathbf{P}$ & $\mathbf{C r}$ & $\mathbf{N i}$ & $\mathbf{M} \mathbf{~}$ \\
\hline P91 & 0.11 & 0.41 & 0.43 & 0.005 & 0.012 & 8.3 & 0.11 & 0.96 \\
\hline P92 & 0.08 & 0.09 & 0.42 & 0.006 & 0.001 & 8.9 & 0.02 & 0.49 \\
\hline ODS(1) & 0.021 & 0.12 & 0.36 & 0.007 & 0.002 & 9 & 0.05 & 0.02 \\
\hline ODS(2) & 0.035 & 0.03 & 0.4 & 0.011 & 0.001 & 9.2 & 0.03 & 0.02 \\
\hline PM 2000 & 0.005 & 0.02 & 0.08 & 0.001 & 0.007 & 20.1 & 0.03 & 0.09 \\
\hline $\mathbf{3 1 6 N G}$ & 0.014 & 0.42 & 0.8 & 0.001 & 0.032 & 16.6 & 11.3 & 2.11 \\
\hline $\mathbf{1 . 4 9 7 0}$ & 0.095 & 0.53 & 1.68 & 0.001 & 0.007 & 15 & 15.3 & 1.18 \\
\hline BG A4 & 0.11 & 0.49 & 6.1 & 0.024 & 0.02 & 22.9 & 15.4 & 0.14 \\
\hline $\mathbf{3 4 7 H}$ & 0.048 & 0.29 & 1.84 & 0.013 & 0.026 & 17.58 & 10.7 & \\
\hline $\mathbf{8 0 0 H}$ & 0.06 & 0.36 & 0.67 & 0.003 & 0.01 & 20.5 & 30.8 & 0.13 \\
\hline $\mathbf{6 2 5}$ & 0.02 & 0.07 & 0.05 & 0.005 & 0.001 & 22.4 & bal. & 9.1 \\
\hline & $\mathbf{C u}$ & $\mathbf{A l}$ & $\mathbf{W}$ & $\mathbf{V}$ & $\mathrm{Ti}$ & $\mathbf{C o}$ & $\mathbf{N b}$ & $\mathbf{F e}$ \\
\hline P91 & 0.02 & 0.01 & $<0,01$ & 0.23 & $<0,003$ & $<0,01$ & 0.05 & bal. \\
\hline P92 & $<0,01$ & $<0,01$ & 2.1 & 0.22 & $<0,01$ & $<0,01$ & 0.05 & bal. \\
\hline ODS(1) & $<0,01$ & $<0,01$ & 1.3 & 0.21 & $<0,003$ & 0.01 & $<0,01$ & bal. \\
\hline ODS(2) & $<0,01$ & $<0,01$ & 1.3 & 0.21 & $<0,003$ & 0.01 & $<0,01$ & bal. \\
\hline PM 2000 & $<0,01$ & 5.5 & $<0,01$ & 0.03 & 0.43 & 0.04 & 0.03 & bal. \\
\hline $\mathbf{3 1 6 N G}$ & 0.23 & 0.007 & 0.02 & 0.04 & 0.004 & 0.07 & 0.01 & bal. \\
\hline $\mathbf{1 . 4 9 7 0}$ & 0.02 & 0.05 & $<0,01$ & 0.02 & 0.45 & 0.03 & & bal. \\
\hline BG 44 & 2.7 & & 1.49 & 0.31 & & & 0.61 & bal. \\
\hline $\mathbf{3 4 7 H}$ & & & & & & & 0.56 & bal. \\
\hline $\mathbf{8 0 0 H}$ & 0.06 & 0.26 & $<0,01$ & 0.04 & 0.36 & 0.09 & 0.01 & bal. \\
\hline $\mathbf{6 2 5}$ & 0.03 & 0.29 & 0.12 & $<0,01$ & 0.25 & 0.06 & 3.3 & 2.6 \\
\hline
\end{tabular}

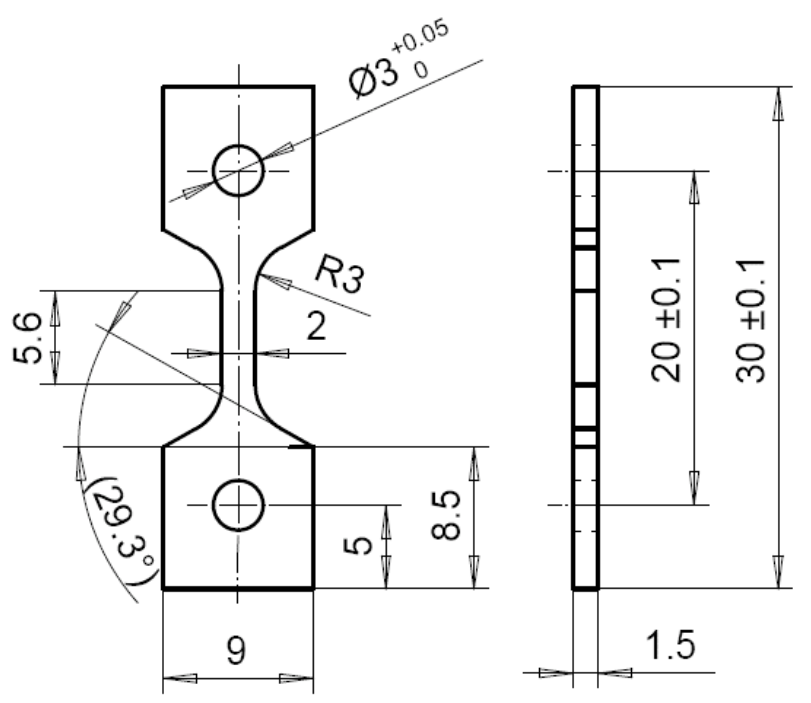

Figure 4. The SSRT specimen geometry and dimensions used for SCWR tests at VTT. 


\subsection{Test procedures}

\subsubsection{General corrosion tests}

The initial weight gain tests (general corrosion tests) were conducted in supercritical water at $400^{\circ} \mathrm{C}$ to $650^{\circ} \mathrm{C}$ under the pressure of $25 \mathrm{MPa}$. The exposure times were up to 600 hours. The test solution was demineralized pure water. During the experiments the inlet water conductivity was $<0.1 \quad \mathrm{~S} / \mathrm{cm}$. The dissolved oxygen content of inlet water was maintained at 0 or between 100 and $150 \mathrm{ppb}$ depending on the test.

The effect of different surface treatments were studied on some coupons and also tubular specimens in order to clarify the effect of deformation in the near-surface regions on the oxidation rate. The surface region deformation was assumed to change the diffusion characteristics of elements by producing higher density of diffusion baths in addition to the already existing grain boundaries. The different surface roughnesses were achieved by machining, or machining combined with polishing with \#600 or \#1200 emery paper. These treatments were performed for austenitic stainless steels $316 \mathrm{NG}$ and 1.4970 . The other alloys were polished with \#1200 emery paper after machining.

After general corrosion test, i.e. weight gain test, the specimens were studied using scanning electron microscopy (SEM) and energy dispersive spectroscopy (EDS).

\subsubsection{Stress corrosion cracking tests}

Stress corrosion cracking (SCC) susceptibilities of five selected alloys were studied at $500^{\circ} \mathrm{C}$ and $650^{\circ} \mathrm{C}$ under SCW conditions. Slow strain rate tests (SSRT) were performed using a step motor controlled loading device. The samples were loaded with a nominal strain rate rate of $3 \times 10^{-7} \mathrm{~s}^{-1}$. During the SSRT experiments the inlet water conductivity was below $0.1 \mu \mathrm{S} / \mathrm{cm}$. The oxygen content was maintained between $100-150$ ppb. After SSRT experiments, samples were examined using an SEM in order to characterize the cracking mode on the fracture and the gauge surfaces. Some samples were cross-sectioned in order to determine the nature of the cracking mode on the side surfaces (IG or TG).

\subsubsection{Test equipment}

The specimens were exposed to high temperature water in a supercritical autoclave, which was connected to a recirculation water loop, Fig. 5. The high pressure loop consists of a high pressure pump, heat exchanger and pre-heater. The water returning from the autoclave flows through the heat exchanger and cooler. The maximum working temperature and pressure of the system is $700^{\circ} \mathrm{C}$ and $42 \mathrm{MPa}$, respectively. The high pressure loop is pressurised using a diaphragm pump and a back pressure regulator. The maximum flow rate of the high pressure loop is $5 \mathrm{dm}^{3} / \mathrm{h}$. The main construction material of the loop is $316 \mathrm{~L}$ and the autoclave is mainly constructed of Nimonic 80A. 


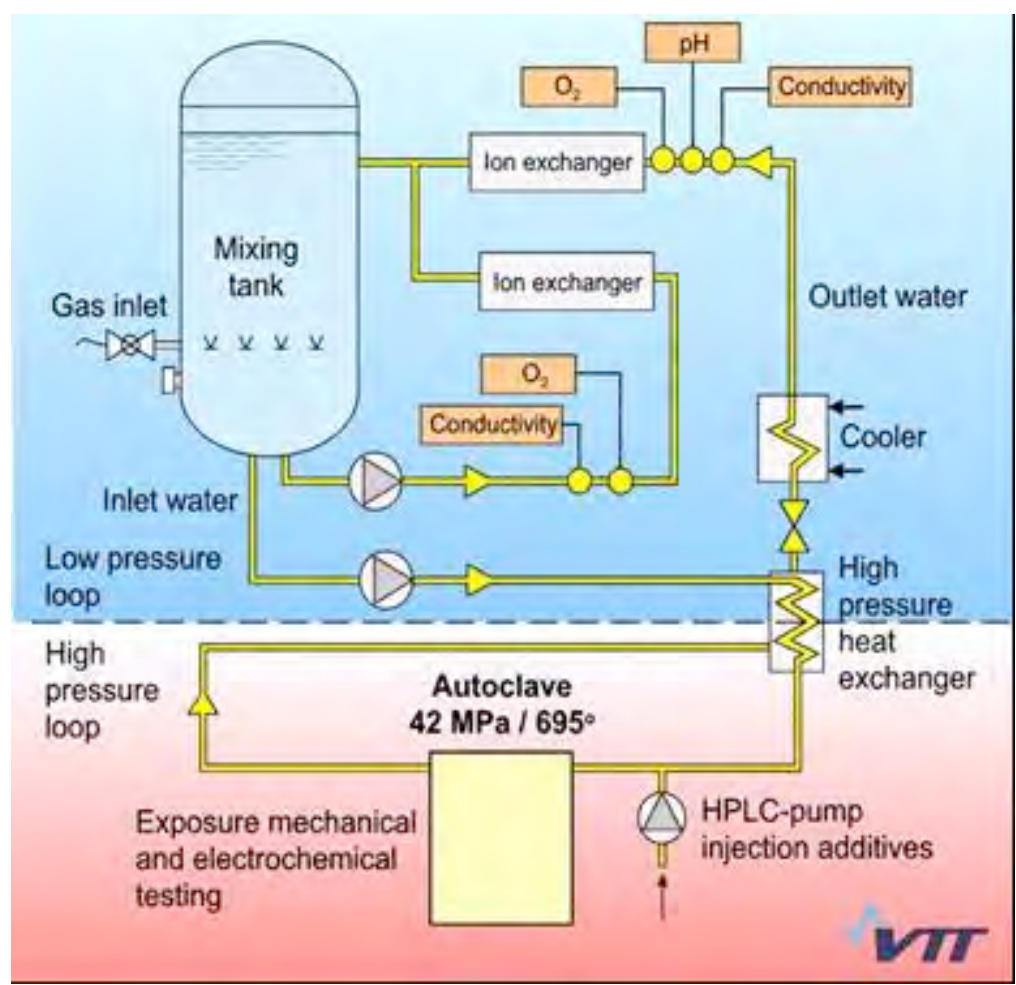

Figure 5. A schematic presentation of the SCW-autoclave system at VTT. The system consists of low and high pressure water recirculation loops in addition to the materials testing autoclave.

\section{RESULTS AND DISCUSSION}

A summary of the general corrosion test results is shown in Fig. 6. More detailed results are presented elsewhere (Penttilä et al., 2008 and Penttilä et al., 2009). Generally, the tested materials showed similar trend, i.e. the weight gain was increased with increasing temperature. The results show that the most corrosion resistant alloys under SCW conditions are high chromium $(>18 \% \mathrm{Cr})$ and high nickel $(>15 \% \mathrm{Ni})$ alloys, which include PM2000, some of the stainless steels, e.g. BGA4 and 800H, and Ni-based alloy 625 .

Based on the general corrosion rate of PM 2000 at $650^{\circ} \mathrm{C}$ and due to its low nickel content, it was selected for the fuel rod cladding material at the present design state of HPLWR. The oxidation behaviour, e.g. oxidation rate and oxide structure, depend highly on the alloy composition and temperature and also on the morphology of the grain structure and degree of surface cold work. The weight gain results shown in Fig. 6 were measured on specimens polished with \#1200 emery paper after machining. 


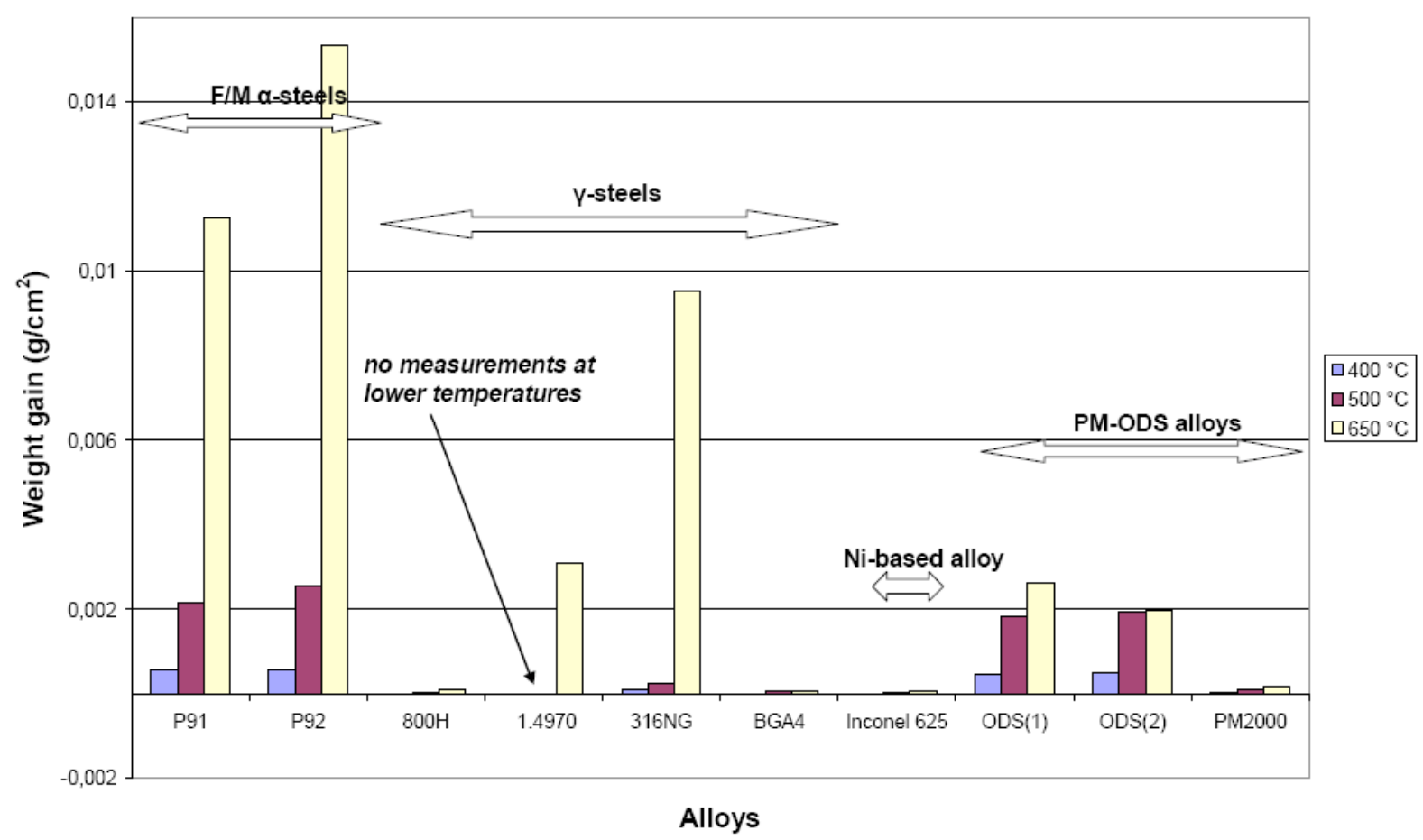

Figure 6. The weight gain test results of the EU HPLWR Phase 2 material programme for candidate in-core materials. The exposure time is $600 \mathrm{~h}$ and the water chemistry is pure water with $125 \mathrm{ppb}$ oxygen, Penttilä et al. (2009).

Recent results reported for the SCWR material tests have showed that approach for candidate alloy selection is challenging. Combination of adequate material properties considering surface and bulk properties cannot be acquired with any single commercial alloy. This means that compromises must be made. An ideal candidate material would be a substrate with good SCC, creep and irradiation resistance and with a surface layer that has a high corrosion resistance. Zheng et al. (2008) have suggested that surface alloying with different techniques, e.g PVD or CVD, is a promising method to limit the general corrosion rate. However, problems may appear for example with the adhesion between the coating and the underlying substrate under cyclic temperature which can be a critical issue for the further testing.

Another approach for surface modification could be grain refinement. Tan et al. (2008a, 2008b) have indicated that cold working, e.g. shot peening, or thermomechanical processing produce an ultrafine-grained surface with greatly increased fraction of modified grain boundaries, i.e. low- boundaries. The significantly increased $\mathrm{Cr}$ flux via grain boundaries due to grain size refinement probably promotes the formation of the predominant Cr-oxide.

Also based on previously presented (Penttilä et al., 2008 and Penttilä et al., 2009) weight gain test results, the oxide thickness was considered to be dependent on the surface state. Thus the effect of bulk metal surface condition was studied by performing different levels of polishing for the specimens. In Fig. 7 are shown the weight gains of the austenitic stainless steel 316L tube samples with different surface finishes: machined surface, as "received" condition, polished with \#600 emery paper and polished with \#1200 emery. The exposure time was $1000 \mathrm{~h}$ and temperature $650^{\circ} \mathrm{C}$. The weight gain in $316 \mathrm{~L}$ sample with machined surface was smaller compared to all other samples. Supposedly the machined surface produces higher degree of cold work on the sample surface than emery paper polishing. Thus, sample with machined surface should have more lattice imperfections, and thus higher density of preferable diffusion paths, in the near-surface. The decrease in the oxidation rate can be explained by the higher diffusion rate of $\mathrm{Cr}$ leading to a higher $\mathrm{Cr}$ concentration in the outer oxide layer. This reduces the outward iron and inward oxygen diffusion. 


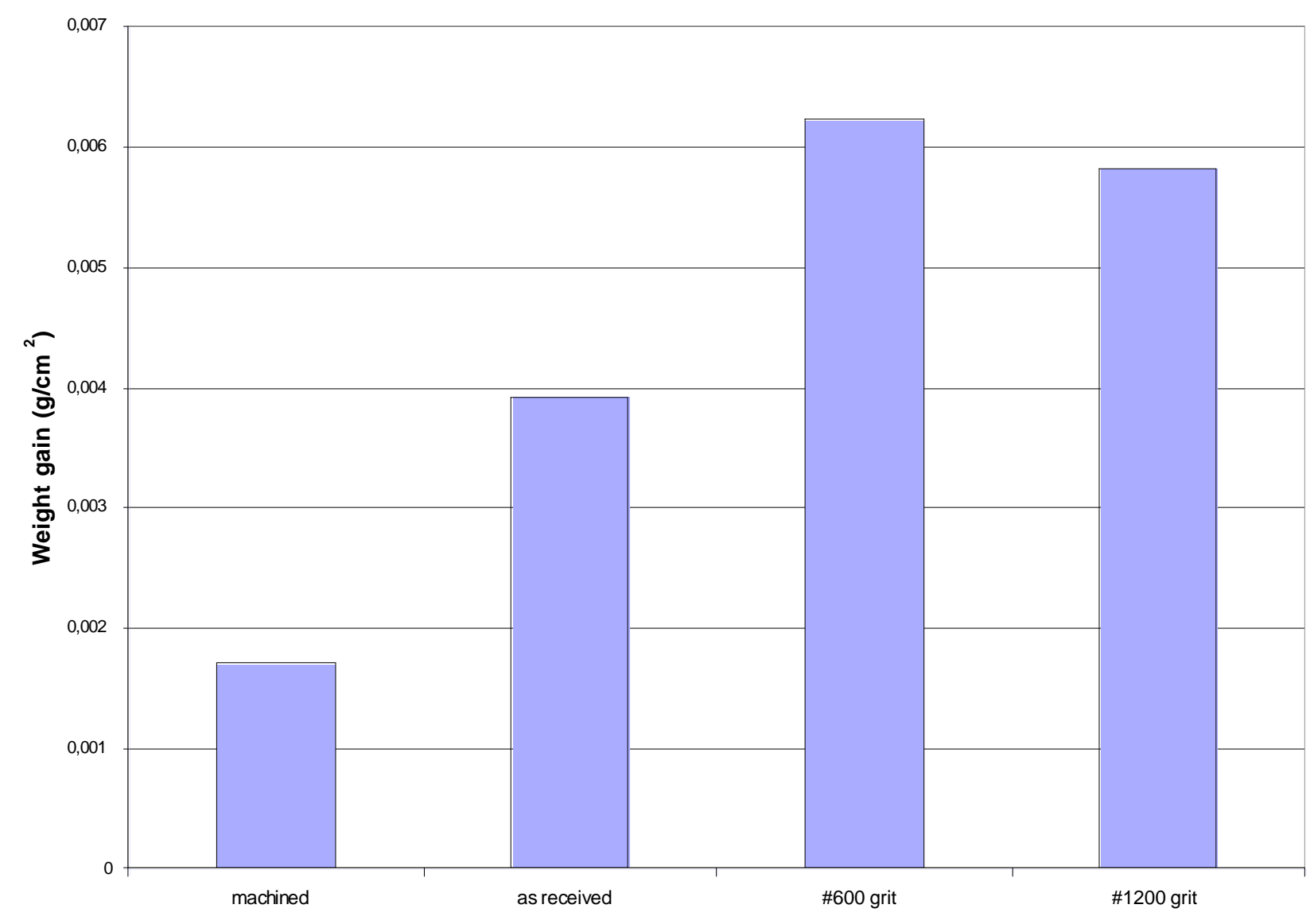

Figure 7. Weight gains of the 316L samples with different surface finishes after $1000 \mathrm{~h}$ exposure under SCW conditions at $650^{\circ} \mathrm{C}$ and $25 \mathrm{MPa}$. The specimens in this figure correspond with specimens 1-4 in Fig. 8, respectively.

In Fig. 8 the oxidised 316L tubes are presented. It is noticeable that the machined sample (sample \#1) has a transparent oxide layer. The transparent oxide layer has a very small contribution to the weight gain shown in Fig. 7 as the inner surface of the tube was in an as received condition and exposed to the SCW, i.e., the weight gain could be expected to be about half of that of the tube fully in an as received condition.

The EDS analysis revealed enriched Mn (4.7 wt- $\%$ ) in the outer oxide layer of the machined 316L tube sample (\#1). Generally, chromium oxide can evaporate at high temperatures in the presence of oxygen and/or water vapour. Holcomb et al. (2006) have stated that when sufficient $\mathrm{Mn}$ is available the formation of $\mathrm{Mn}$ $\mathrm{Cr}$-spinels can occur. Presumably formation of $\mathrm{Cr}$ spinels with $\mathrm{Mn}$ decreases the $\mathrm{Cr}$ activity and might mitigate the Cr volatilization under SCW conditions (forming e.g. $\mathrm{MnCr}_{2} \mathrm{O}_{4}$ ). 


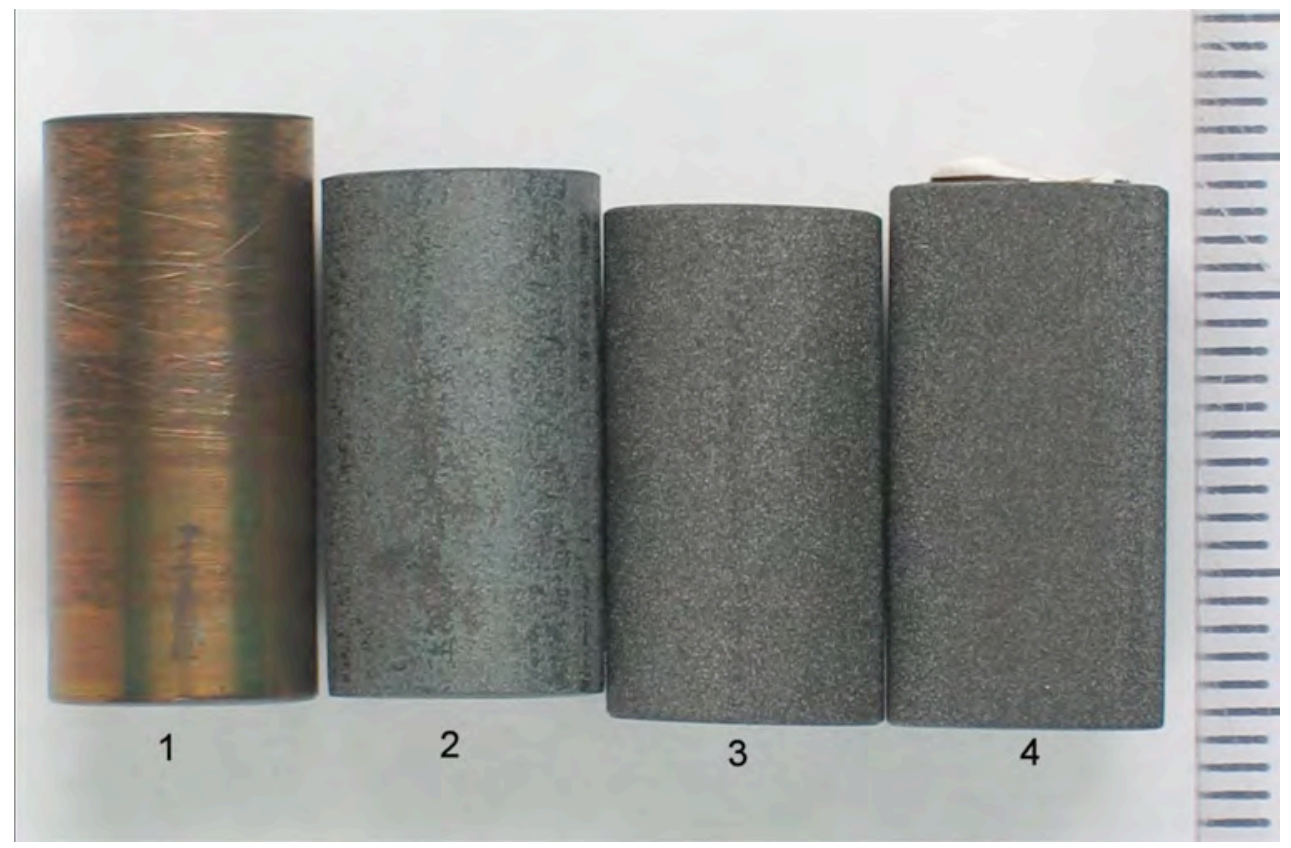

Figure 8. $316 \mathrm{~L}$ tube samples after $1000 \mathrm{~h}$ exposure under SCW conditions at $650^{\circ} \mathrm{C}$ : Sample 1) machined with blunt edge hard metal cutting tool, 2) "as received", 3) surface finish with \#600 emery paper and 4) with \#1200 emery paper.

The cross-sections of the samples polished with \#1200 emery paper and in as machined condition after the exposure can be seen in Fig. 9 a and b, respectively. The oxide thickness of the polished sample is about 40-50 $\mathrm{m}$ whereas the oxide thickness in the machined sample is in the range of 1-2 $\mathrm{m}$ at maximum. Peng et al. (2005) have demonstrated that the growth of the protective $\mathrm{Cr}$-rich oxide layer could be maintained when a large number of new grain boundaries serve as channels for $\mathrm{Cr}$ diffusion in wet air atmospheres (700 $-900^{\circ} \mathrm{C}$ ). Hence, this enhanced diffusion is fast enough to balance the consumption rate of $\mathrm{Cr}$ by vaporization and by oxidation in wet air conditions where chromia evaporation is a considerable factor.

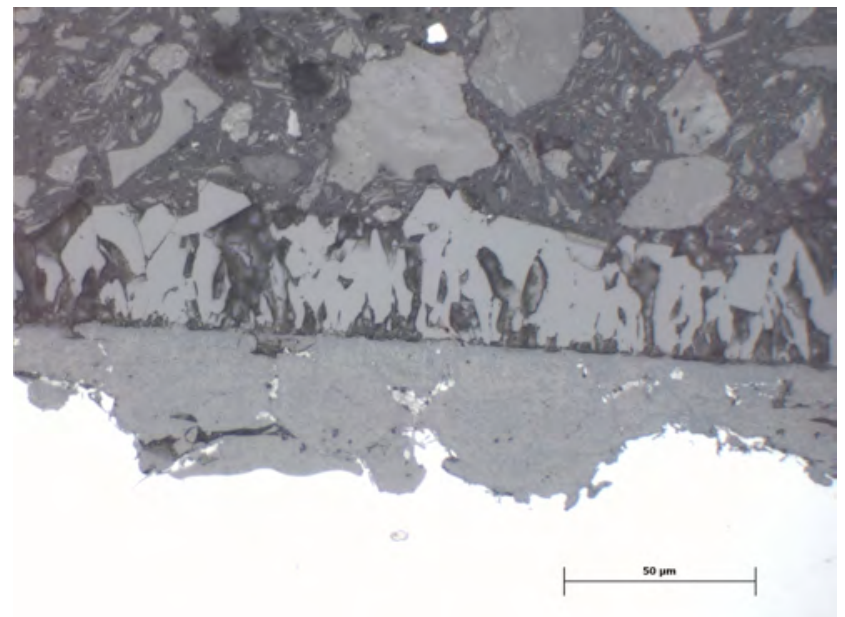

a)

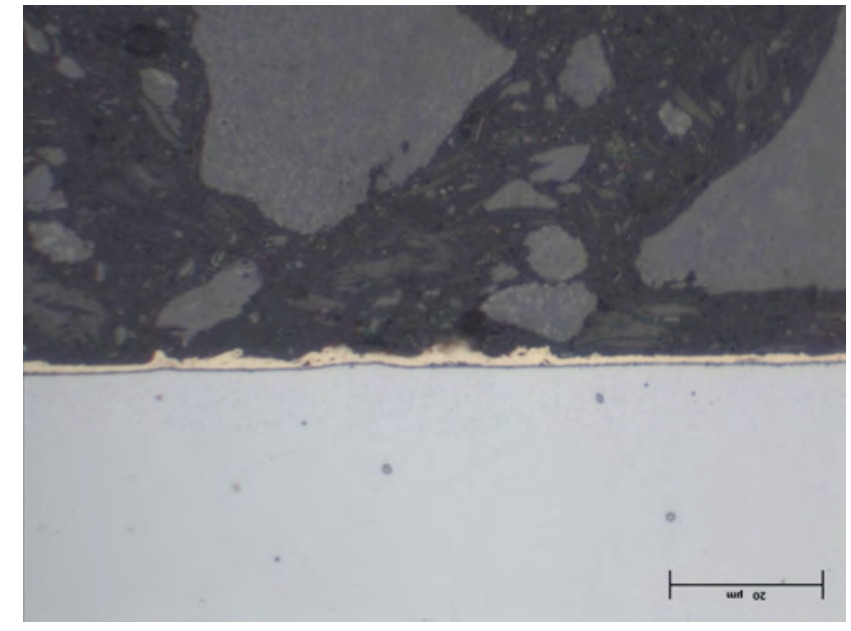

b)

Figure 9. Cross-sections of the $316 \mathrm{~L}$ tube samples, a) polished with \#1200 emery paper and b) as machined condition after $1000 \mathrm{~h}$ exposure under SCW conditions at $650^{\circ} \mathrm{C}$. Base metal in the lower and resin in the upper part of the photographs. The scaling line in both photographs $50 \mathrm{~m}$ long. 
Peng et al. (2005) interpret the Cr diffusion phenomenon in the metal using a summation of lattice diffusivity $\left(\mathrm{D}_{\mathrm{L}}\right)$ and grain boundary diffusion $\left(\mathrm{D}_{\mathrm{GB}}\right)$ as follows:

$$
D_{\text {eff }}=D_{L}+\frac{2 \delta}{d} D_{G B}
$$

where an effective diffusivity of $\mathrm{Cr}\left(\mathrm{D}_{\text {eff }}\right)$ increases when the grain size (d) decreases ( is the grain boundary width). Based on the grain refinement for example using cold work (which introduces also possibly beneficial diffusion paths within the grains, i.e., dislocations), it is possible that modified austenitic stainless steels are available for applications where temperatures are higher than $500^{\circ} \mathrm{C}$ without the need of increasing the bulk Cr concentration.

As mentioned above, it is evident that grain boundaries are fast diffusion paths. Due to supposed recovery process of the cold-worked area, increased density of low- boundaries might occur in the cold worked sample. Tan et al. (2008) have showed that increased density of low- boundaries do not favour fast diffusion and thus decrease the overall diffusivity along grain boundaries. In that case overall diffusivity moves closer to the bulk diffusivity and the outward/inward transport of $\mathrm{Fe} / \mathrm{O}$ decreases at least a certain extent. When grain boundary diffusivity is expected to be much closer to the bulk diffusivity, compact oxide scale with a continuous Cr-rich oxide layer is anticipated due to relatively uniform diffusivity to the free surface of the samples.

\subsection{SCC susceptibility of candidate materials}

Many austenitic alloys have been tested in SCW conditions comparatively widely with different dissolved oxygen contents $(10 \mathrm{ppb}-8 \mathrm{ppm})$. However, temperature is usually limited below $550^{\circ} \mathrm{C}$, although the fuel cladding peak temperature is expected to be higher. The existing database in literature is very diverse and the comparison of the SCC results directly is difficult due to the differences in the experimental conditions used. In general, SCC tests on austenitic alloys (e. g. 304, 316 and 347) have showed that SCC is a significant problem throughout the SCWR temperature range, i.e. from $290^{\circ} \mathrm{C}$ to $550^{\circ} \mathrm{C}$. All of these austenitic alloys have showed at least some sort of SCC and most of it has been IGSCC. At the moment, very little data is available in open literature on the SCC susceptibility of ODS steels under SCW conditions. Ni-base alloys have been shown to be SCC susceptible in SCW conditions. On the other hand, ferritic-martensitic forged steels seem to be SCC resistant in the same conditions.

Austenitic alloys 316NG, 1.4970, 347H and BGA4, and F/M ODS steel PM2000 were tested within HPLWR Phase 2. The measured stress-strain curves are shown in Fig. 10a and b, respectively.

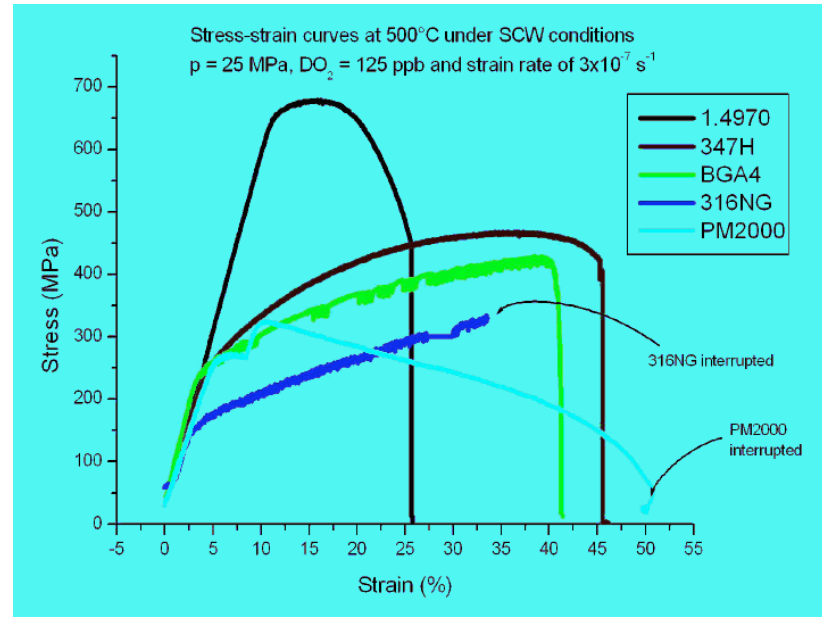

a)

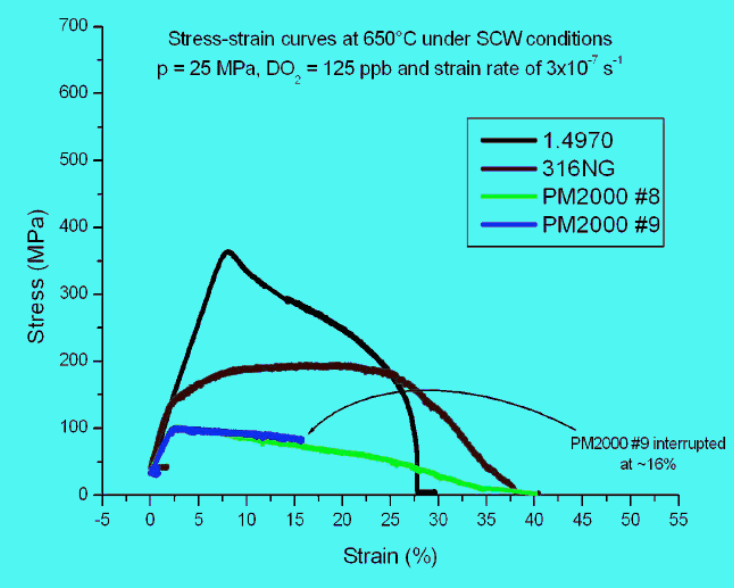

b)

Figure 10. Stress-strain curves for the studied alloys measured in $\mathrm{SCW}$ at a) $500^{\circ} \mathrm{C}$ and b) $650^{\circ} \mathrm{C}$, the strain rate is $3 \times 10^{-7} \mathrm{~s}^{-1}$ for both temperatures. 
All austenitic stainless steels exhibited strain hardening at $500^{\circ} \mathrm{C}$ although the degree of strain hardening of cold worked alloy 1.4970 was rather low. Cold work decreases the strain to failure, which can be seen in Fig. 10a when 1.4970 steel is compared to the other austenitic stainless steels. The oxide dispersion strengthened steel PM2000 shows two different yielding values because the specimen was loaded using a strain rate of $3 \times 10^{-8} \mathrm{~s}^{-1}$ in the beginning after which the strain rate was increased to $3 \times 10^{-7} \mathrm{~s}^{-1}$ (at about $10 \%$ strain). The sudden increase in the stress level when the strain rate was changed indicates that there is a time dependent component present in the stress-strain behaviour, i.e., creep. When Figures 10a and $10 \mathrm{~b}$ are compared, it is evident that the test temperature in this regime has a considerable influence in the stress-strain behaviour of all of the tested alloys. All strength values have decreased considerably as the test temperature has been increased from $500^{\circ} \mathrm{C}$ to $650^{\circ} \mathrm{C}$. Especially the decrease in the yield stress of PM2000 is remarkable. The yield stress decreased to $\sim 1 / 3$ of the value at $500^{\circ} \mathrm{C}$ tested at $650^{\circ} \mathrm{C}$. The reason for this vast decrease is not clear at the moment, but apparently it is related to a prior thermal treatment of the alloy. The decrease in the yield stress was confirmed by performing a second test (sample PM2000 \#9 interrupted at $\sim 16 \%$ strain) using the same test parameters with the same result.

An example of fracture surface of a SSRT specimen is shown in Fig. 11. Post test SEM studies of the SSRT specimens showed that $316 \mathrm{NG}, 1.4970$ and $347 \mathrm{H}$ are possibly susceptible to $\mathrm{SCC}$ at $500^{\circ} \mathrm{C}$. No clear signs of SCC were observed on the fracture surfaces, but on side surfaces there were small cracks. However, the morphology of these cracks could not be identified except in the case of 316NG (which had both interand transgranular cracks, IGSCC and TGSCC). On the other hand, the experimental creep resistant steel BGA4 specimen contained IGSCC both on the fracture surface and side surfaces. At $500^{\circ} \mathrm{C}$, the ODS alloy PM2000 did not show any susceptibility to SCC at all.

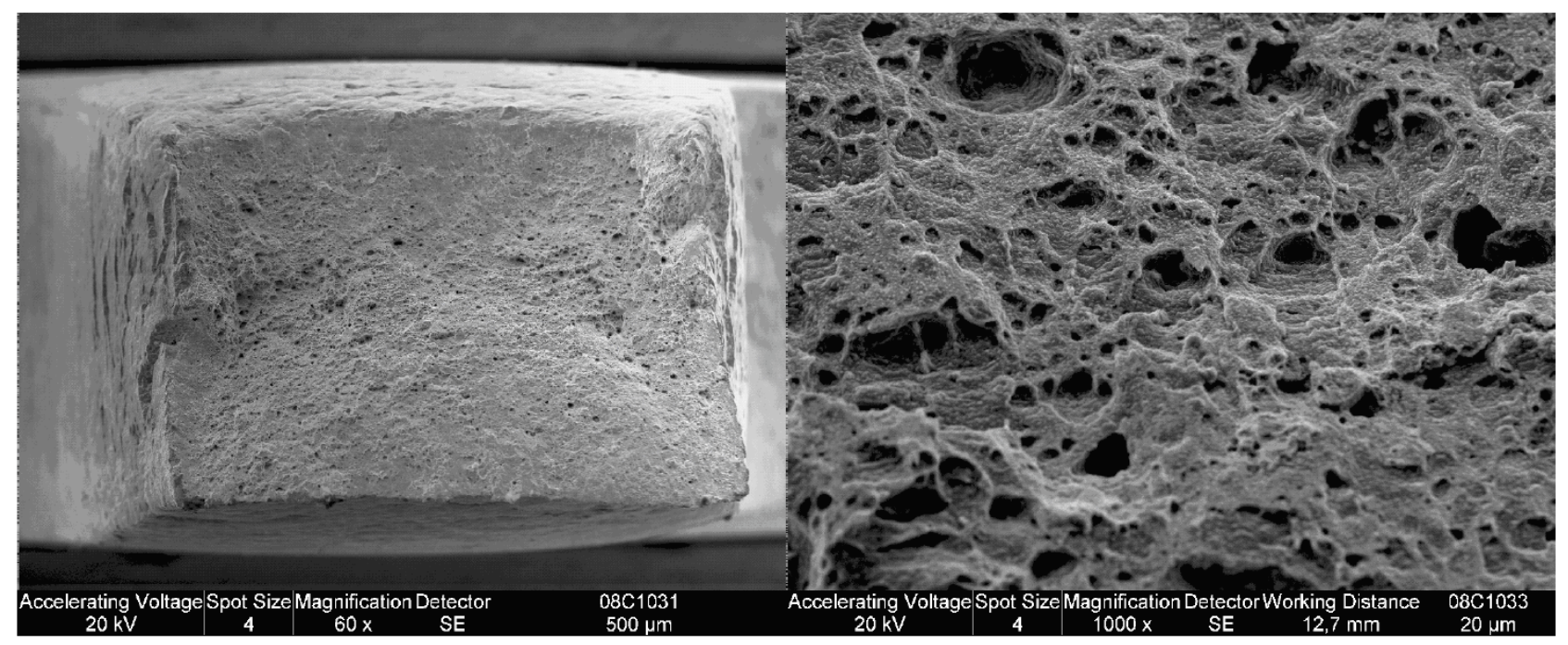

Figure 11. SEM-images of the fracture surface of alloy 1.4970 after SSRT at $500^{\circ} \mathrm{C}$.

Post test SEM examination of $316 \mathrm{NG}$ specimen after the test at $650^{\circ} \mathrm{C}$ revealed both IGSCC and TGSCC on the fracture surface, but no cracks were observed on the side surfaces. The fracture surface of the 1.4970 specimen was badly oxidized and the fracture morphology could not be identified. This specimen had also cracks on the side surfaces, but as after the test at $500^{\circ} \mathrm{C}$, the morphology did not have clear transgranular or intergranular features. PM2000 did not show any stress corrosion or other types of cracking, but necking had occurred until the specimen failed (i.e., the fracture location was almost "knife edge" sharp). The main observation made from the SSRT tests are collected into Table 2. 
Table 2. Summary of SCC susceptibility after SSRT test at 500 and $650^{\circ} \mathrm{C}$.

\begin{tabular}{|c|c|c|c|c|c|}
\hline$\widehat{A l l o y}$ & \begin{tabular}{|l|} 
Maximum \\
stress \\
(MPa)
\end{tabular} & $\begin{array}{l}\text { Strain to } \\
\text { failure }(\%)\end{array}$ & $\begin{array}{l}\text { TGSCC } \\
(\mathbf{y} / \mathbf{n})\end{array}$ & \begin{tabular}{|l|} 
IGSCCC \\
$(\mathbf{y} / \mathbf{n})$
\end{tabular} & $\begin{array}{l}\text { Side craks at } \\
\text { the gauge } \\
\text { surface }(y / n)\end{array}$ \\
\hline $\begin{array}{l}347 \mathrm{H} \\
\text { a } 500^{\circ} \mathrm{C}\end{array}$ & 465 & 45 & No & No & $\begin{array}{c}\text { Yes, morphology } \\
\text { not identified }\end{array}$ \\
\hline $\begin{array}{l}347 \mathrm{H} \\
\text { (a) } 650^{\circ} \mathrm{C}\end{array}$ & NA & NA & $\overline{\text { NA }}$ & NA & NA \\
\hline $\begin{array}{l}\text { 316NG } \\
@ 500^{\circ} \mathrm{C}\end{array}$ & $\begin{array}{c}\text { Interrupted } \\
\text { at } 330\end{array}$ & $\begin{array}{c}\text { Interrupted at } \\
33\end{array}$ & $\overline{\mathrm{NA}}$ & NA & Yes, IG and TG \\
\hline $\begin{array}{l}316 \mathrm{NG} \\
\left(650^{\circ} \mathrm{C}\right.\end{array}$ & 195 & 38 & Yes & Yes & No \\
\hline $\begin{array}{l}1.4970 \\
@ 500^{\circ} \mathrm{C}\end{array}$ & 675 & 26 & No & $\overline{\text { No }}$ & $\begin{array}{c}\text { Yes, morphology } \\
\text { not identified }\end{array}$ \\
\hline $\begin{array}{l}1.4970 \\
@ 650^{\circ} \mathrm{C}\end{array}$ & 360 & 28 & $\begin{array}{c}\text { Badly } \\
\text { oxidized }\end{array}$ & \begin{tabular}{|c|}
$\begin{array}{c}\text { Badly } \\
\text { oxidized }\end{array}$ \\
\end{tabular} & $\begin{array}{c}\text { Yes, morphology } \\
\text { not identified }\end{array}$ \\
\hline \begin{tabular}{|l} 
BGA4 \\
(a $500^{\circ} \mathrm{C}$
\end{tabular} & 425 & 41 & Yes & Yes & Yes, IG \\
\hline \begin{tabular}{|l} 
BGA4 \\
a $650^{\circ} \mathrm{C}$
\end{tabular} & $\overline{\mathrm{NA}}$ & $\overline{\mathrm{NA}}$ & $\overline{\mathrm{NA}}$ & $\overline{\mathrm{NA}}$ & $\overline{\mathrm{NA}}$ \\
\hline $\begin{array}{l}\text { PM2000 } \\
@ 500^{\circ} \mathrm{C}\end{array}$ & 325 & $\begin{array}{c}\text { Interrupted at } \\
50\end{array}$ & No & No & No \\
\hline $\begin{array}{l}\text { PM2000 \#8 } \\
\text { @ } 650^{\circ} \mathrm{C}\end{array}$ & 100 & 40 & No & No & No \\
\hline
\end{tabular}

\section{CONCLUSIONS}

The materials issues are critical in developing new energy concepts with high operating temperatures and especially when neutron flux is involved. Part of the construction material issues in GenIV development are concept specific but many are still common to all or most of the concepts. There are many technologies and facilities to be developed besides the new material development itself in order to meet the GenIV requirements and also to make these concepts possible. Especially the development of test loops for the materials performance testing and carrying out irradiation tests at relevant environmental conditions would be necessary. Research and development of the welding and weldability and manufacturing issues are needed for the realisation of structural components. Later on the development of suitable NDE technologies will be required to verify the acceptance criteria for the components and to demonstrate the plant life management concepts for the new processes.

For the thin-walled components in the design of an SCWR, corrosion, stress corrosion cracking and creep resistance are anticipated to be the most severe degradation modes that need to be understood and controlled. The oxidation rates have to be lower than what is acceptable for materials in supercritical fossil power plants because of the smaller wall thicknesses in the SCWR core component designs. In supercritical fossil power plants $\mathrm{F} / \mathrm{M}$ steels are typically used because of their good creep strength up to $>600^{\circ} \mathrm{C}$. However, the oxidation rate of F/M steels is too high for the SCWR core components even at the temperatures below $500^{\circ} \mathrm{C}$. The austenitic stainless steels, which have an acceptable oxidation resistance up to $500-550^{\circ} \mathrm{C}$ and thus the alloy type has been selected as the candidate material for most of the European SCWR, i.e., HPLWR, core components. The $20 \%$ Cr ODS steel studied was selected for the fuel cladding first because of its excellent oxidation resistance even up to $650^{\circ} \mathrm{C}$. Second, its SCC resistance and its good creep specifications are good as well. However, the SSRT results in this work are not in line with the creep strength specifications of the material manufacturer. Therefore, more studies are needed in the behaviour of high $\mathrm{Cr}$ F/M ODS steels in supercritical water. Also, other problems exist with the use of ODS materials, 
mainly linked to the difficulties in welding and other manufacturing technologies. Therefore these ODSmaterials are recommended only for applications where high strength (with reserve) and oxidation resistance are needed, but only little manufacturing or assembly is required.

The second possible road for fuel cladding development, if ODS steels appear not to be a feasible solution, may be use of coating on austenitic stainless steels or F/M steels. Several coating materials and deposition processes are currently being studied by several institutes for steam plant components. Processes that have been studied are diffusion coating (i.e. slurry application, CVD) and overlay coating (thermal spray, PVD, electroless coatings), Aguero (2008) and Zheng et al. (2008).

The third possibility is cold working of the surface region of austenitic stainless steels, which appears to suppress oxidation up to $650^{\circ} \mathrm{C}$ for a substantial exposure time. However, this needs to be verified by longer exposure times than used in this study.

Acknowledgements. The financial support of European project HPLWR Phase 2 and Academy of Finland project SusEn NETNUC are gratefully acknowledged.

\section{REFERENCES}

Aguero, A. 2008. Coatings for steam power plants, Instituto Nacional de Técnica Aeroespacial (INTA), COST 536 Training School, October 2008, Lanzarote, Spain.

Heikinheimo, L., Aaltonen, P. and Toivonen, A. 2007. Generation IV Material Issues. Baltica VII, International Conference on Life Management and Maintenance for Power Plants. Helsinki - Stockholm Helsinki, 12-14 June.

Heikinheimo, L., Guzonas, D. and Fazio, C. 2009. GenIV materials and chemistry research - common issues with the SCWR concept. 4th International Symposium on Supercritical Water-Cooled Reactors. March 8-11, Heidelberg, Germany, Paper No. 81.

Holcomb, G. R., Alman, D. E. 2006. The effect of manganese additions on the reactive evaporation of chromium in Ni-Cr alloys. Scripta Materialia. Vol. 54. P. 1821-1825.

Peng, X., Yan, J., Zhou, Y., Wang, F. 2005. Effect of grain refinement on the resistance of 304 stainless steel to breakaway oxidation in wet air. Acta Materialia. Vol. 53. P. 5079-5088.

Penttilä, S., Toivonen, A., Heikinheimo,L. and Novotny, R. 2008. Corrosion studies of candidate materials for European HPLWR. Proceedings of ICAPP '08, Anaheim, CA USA, June 8-12, Paper 8164.

Penttilä, S., Toivonen, A., Heikinheimo, L. and Novotny, R. 2009. SCC properties and oxidation behaviour of austenitic alloys at supercritical water conditions. 4th International Symposium on Supercritical WaterCooled Reactors, March 8-11, Heidelberg, Germany, Paper No. 60.

Tan, L., Sridharan, K., Allen, T., Nanstad, R., McClintock, D. 2008. Microstructure tailoring for property improvements by grain boundary engineering. Journal of Nuclear Materials. Vol. 374. P. 270-280.

Tan, L., Ren, X., Sridharan, K., Allen, T. 2008. Effect of shot-peening on the oxidation of alloy $800 \mathrm{H}$ exposed to supercritical water and cyclic oxidation. Corrosion Science. Vol. 50. P. 2040-2046.

Weisenburger, A. Heinzel, A. Müller, G. et al. 2008. Journal of Nuclear Materials. Vol. 376. P. 274-281.

Zheng, W., Guzonas, D., Wills, J. and Li, J. 2008. Novel approach to the development of in-core materials for a supercritical water cooled reactor. 16th Pacific Basin Nuclear Conference (16PNC), Oct. 13-18, Aomori, Japan. PaperID P16P1413. 